\title{
Health Status and Behaviors of Greeks and Americans
}

\author{
By Mildred Naquin * \\ Janet Jones ${ }^{\dagger}$ \\ Wynn Gillan ${ }^{*}$ \\ Marie Zannis \\ Ifigenia Georgiadou \\ Corinne Cormier ${ }^{+}$ \\ Jessica Friley
}

Differences in the health status and health behaviors of individuals in diverse countries have become of increasing interest. This study examined the health status and health behaviors of the Greek people as compared to citizens of the United States of America (USA). It also provided insights on the health assets of each country, areas in which each country can improve, and how behaviors and cultural differences influence the public health of a nation. Methods of study included observation and interviewing while in Greece, and comparisons of surveillance systems of both nations. Visits were made to private and public health clinics in Greece, as well as to the Greek Ministry of Health, and the Greek Council on Refugees. Selected research studies were also examined. Conclusions were made based on the collection of interviews, observations, public statistics, and research study findings. In further pursuing the health status of Greeks and Americans, four health behaviors were targeted for this study including use of tobacco, nutritional practices, exercise/physical activity, and sleep patterns. Although in 2014, the American death rate was lower (823.7 per 100,000 population) than in Greece (1,041 per 100,000), the average life expectancy was similar in the two countries: 79.8 years in the USA and 80.5 years in Greece. For adults, 56.2\% of Greeks are overweight or obese compared to $69.8 \%$ of Americans. Many Greeks and Americans do not participate in enough physical activity, 46.6\% of Greek adults and $80 \%$ of Americans. Greeks typically follow the Mediterranean Diet, but because of economic and sociological factors, recently their diets have been changing to include more convenience foods. Americans are advised to follow the United States Department of Agriculture's MyPlate and the US Dietary Guidelines. However, Americans frequently consume fast foods. Greece has twice the overall prevalence of smoking (40\%) than the USA (19\%), and in both nations males smoke more than females. American youth use electronic cigarettes more than regular cigarettes, unlike Greek youth who usually smoke regular cigarettes. In some regions of Greece, midday napping is still practiced which can provide numerous health benefits including increased alertness and

* Professor, Department of Kinesiology and Health Studies, Southeastern Louisiana University, Hammond, Louisiana, USA.

$\dagger$ Assistant Professor, Department of Nursing, Southeastern Louisiana University, Hammond, Louisiana, USA.

* Assistant Professor, Department of Kinesiology and Health Studies, Southeastern Louisiana University, Hammond, Louisiana, USA.

Associate Professor, Nicholls State University, Thibodaux, Louisiana, USA, Retired.

- Director, Hellenic Culture Center, Megalochori, Santorini, Greece.

+ Graduate, Department of Kinesiology and Health Studies, Southeastern Louisiana University, Hammond, Louisiana, USA.

- Graduate Assistant, Department of Kinesiology and Health Studies, Southeastern Louisiana University, Hammond, Louisiana, USA. 
productivity, and reducing the likelihood of death from heart attacks. In both countries, the need for health education and promotion is apparent. The USA supports a vast public health network including public health agencies and universities offering degrees in public health. In Greece such efforts in public health are limited and social marketing of predominant health issues is rare.

Keywords: health promotion, blue zones, public health, Greek population, American population.

\section{Introduction}

Differences in the health status and health behaviors of individuals in diverse countries have gained increasing attention. A keen interest in longevity has been a part of human existence for eons. Answers to questions of which factors specifically influence longevity and optimal health have been elusive. Studying those who live longer may be one way of answering questions about longevity. In certain parts of the world there are individuals who experience unusually extended lifespans (often over 100 years); those areas are known as "Blue Zones" (Poulain et al. 2013). Often these individuals remain physically and mentally active throughout their life.

Longitudinal studies have consistently shown behaviors that promote long, healthy lives including the health benefits of a Mediterranean diet (Sofi et al. 2014), regular physical activity (WHO 2015) and smoking cessation (GBD 2015 Tobacco Collaborators 2017).Comparing behaviors between people living in blue zones and those living in other countries may help elucidate the factors that contribute to a long and productive life. It is reasonable to suspect that the behaviors, cultural practices, environmental influences and lifestyles of people who live in those areas may help explain some of their longevity. One of those areas where people tend to live long and productive lives is the island of Ikaria, Greece (Poulain et al. 2013). Certainly these influences are reflections of the Greek lifestyle. Consequently comparing reported health behaviors between those living in Greece and those in the United States may help to identify specific factors which contribute to a healthy, long and productive life.

\section{Methods}

The purpose of this study was to examine the health status and health behaviors of the Greek people as compared to individuals in the United States of America (USA). These countries were chosen for comparison because of investigators' perceived differences between the two cultures in relation to health behaviors. A mixed methods descriptive study approach was utilized incorporating qualitative interviews and observations with a retrospective examination of vital statistics and public reports with an integrative literature review. The study was found to be exempt from Institutional Review Board governance due to the low risk to participants and public data utilization.

Observation and interviewing were conducted to gather data; this was accomplished by the research of students and faculty in a health science class (Health and Wellness Study Abroad) held in Greece during the summer of 2016. 
Students and faculty members interviewed health professionals including three physicians, two social workers, a midwife, a physiotherapist, a massage therapist, a pharmacist, and a governmental administrator for a total of ten participants. These professionals were chosen for interviews because of their knowledge of and prominence within the health care system, as well as their direct contact with the public. The interviews were arranged purposefully by the Hellenic Cultural Center located in Santorini, Greece and conducted with a Greek interpreter. However, the majority of the conversations were in English. The interviews of health care workers were semi-structured including questions related to professional educational preparation, licensure, practice oversight, continuing education requirements, job responsibilities, reimbursement, and salaries.

To collect information, students and faculty also visited private and public health clinics in Santorini, Greece, as well as the Greek Ministry of Health and the Greek Council on Refugees located in Athens. Observations of these facilities were directed by the faculty and cultural liaison. Emphasis was placed on facility organization, access, resources, funding, reimbursement methods, and health care issues. Administrative representatives from these agencies were interviewed after the observational events. These interviews consisted of semi-structured questions which addressed health behaviors, risk factors, public policy, funding, emerging health care issues, and future strategies. The agency visits were at the end of the Health and Wellness Study and assisted in validating previous interviews and observations. A summary of the professional interview findings and the administrative discussions were compiled and compared among the students and faculty.

In addition, students were directed to observe and interact with the Greek populace throughout their study abroad experience. The students observed the Greek health behaviors such as smoking, dietary practices, physical activity, sleep, utilization of integrative medicine, and the incorporation of spirituality. These findings were recorded in the students' reflective journals.

Finally comparisons of surveillance systems and selected research studies of the two nations were examined by the students and investigators via electronic databases and literature searches. This evidence substantiated the interview and observational findings. Four health behaviors were targeted for study including use of tobacco, nutritional practices, exercise/physical activity, and sleep patterns regarding these behaviors impact on quality of life, mortality, and morbidity.

Data analyses consisted of reviewing the findings of the interviews and observations to identify trends and themes. Three faculty members participated in the interviews and observations. Each kept a reflective journal and notes. A fourth impartial faculty member assisted in reviewing and compiling the information. Descriptive statistics were used to compare the vital statistics and research findings, primarily in terms of frequencies and prevalences. Findings were triangulated among the interviews, observations, public statistics, and research study findings. Differences in opinion among the reviewers were discussed and agreed upon by consensus. 
Vol. 5, No. 1 Naquin et al.: Health Status and Behaviors of Greeks and Americans

\section{Findings}

Demographics

Table 1. Demographics of Greece and the USA

\begin{tabular}{|c|c|c|}
\hline & Greece & USA \\
\hline Size of Country & $131,957 \mathrm{sq} \mathrm{km}$ & $9,833,517 \mathrm{sq} \mathrm{km}$ \\
\hline Population & $10,773,253$ & $323,995,528$ \\
\hline Race / Citizenship & $\begin{array}{l}\text { - Greek } 93 \% \\
\text { - Other (foreign } \\
\text { citizens) } 7 \% \\
\text { Ethnicity data is not } \\
\text { collected in Greece }\end{array}$ & $\begin{array}{l}\text { - White } 79.96 \% \\
\text { - Black } 12.85 \% \\
\text { - Asian } 4.43 \% \\
\text { - American Indian and } \\
\text { - Alaska native } 0.97 \% \\
\text { - Native Hawaiian and other } \\
\text { - Pacific Islander } 0.18 \% \\
\text { - Two or more races } 1.61 \%\end{array}$ \\
\hline Languages & $\begin{array}{l}\text { - Greek (official) } \\
99 \% \\
\text { - Other (includes } \\
\text { English and } \\
\text { French) } 1 \%\end{array}$ & $\begin{array}{l}\text { - English } 79.2 \% \\
\text { - Spanish } 12.9 \% \\
\text { - Other Indo-European } \\
3.8 \% \\
\text { - Asian and Pacific Island } \\
3.3 \% \\
\text { - } \text { Other } 0.9 \%\end{array}$ \\
\hline Religion & $\begin{array}{l}\text { - Greek Orthodox } \\
\text { (official) } 98 \% \text {, } \\
\text { - Muslim } 1.3 \% \text {, } \\
\text { - Other } 0.7 \%\end{array}$ & $\begin{array}{l}\text { - Protestant } 46.5 \% \\
\text { - Roman Catholic } 20.8 \% \\
\text { - Mormon } 1.6 \% \\
\text { - Jehovah's Witness } 0.8 \% \\
\text { - Other Christian } 0.9 \% \\
\text { - Jewish } 1.9 \% \\
\text { - Muslim 0.9\% } \\
\text { - Buddhist or Hindu } 0.7 \% \\
\text { - Other } 1.8 \% \\
\text { - Unaffiliated } 22.8 \% \\
\text { - Don't know/refused } 0.6 \%\end{array}$ \\
\hline Net Migration Rate & 2.3 migrants $/ 1,000$ & 3.9 migrants $/ 1,000$ \\
\hline Urbanization & $\begin{array}{l}78 \% \text { of total } \\
\text { population }\end{array}$ & $81.6 \%$ of total population \\
\hline $\begin{array}{l}\text { Unemployment, Youth } \\
\text { Ages 15-24 }\end{array}$ & $52.4 \%$ & $13.4 \%$ \\
\hline $\begin{array}{l}\text { Percent of Population } \\
\text { Growth }\end{array}$ & $-0.03 \%$ & $0.81 \%$ \\
\hline
\end{tabular}

Source: USA Central Intelligence Agency 2016 
Greece is a small country in comparison to the land mass of the USA; it is about the size of the state of Alabama in the USA and includes thousands of islands. The USA's population is about 30 times that of Greece. In Greece, the predominant language is Greek and the major religion is Greek Orthodox (Christian). In contrast, the USA has a diverse racial and religious population. The USA has small population growth, while Greece has negative growth. Greek youth unemployment exceeds that of youth in the USA (Central Intelligence Agency [CIA] 2016). (See Table 1.)

\section{Health Status}

The top three major causes of death in both the U.S. and Greece are cardiovascular disease, cancer, and respiratory diseases, respectively (Hellenic Statistical Authority [ELSTAT] 2015, Centers for Disease Control and Prevention [CDC] 2017a). Unintentional accidents and violent deaths also caused mortality in both countries. According to the CDC, the USA death rate was 823.7 per 100,000 population in 2014 (2014). That year the death rate in Greece was higher, at 1,041 per 100,000 (ELSTAT 2014). The average life expectancy in the USA is 79.8 years ( 77.5 for males, 82.1 for females); the average life expectancy in Greece is 80.5 years ( 77.9 for males, 83.3 for females) (CIA 2016). The USA infant mortality rate is 5.8 deaths per 1,000 live births, compared to 4.6 in Greece. Among the largest differences in health status of the two nations were the adult obesity rate, with Greece at $25 \%$ and the USA at $35 \%$.

Greece has a constrictive or declining population. The largest age group in Greece currently is 40-44, accounting for $7.5 \%$ of the population, with only $4.6 \%$ of the population under the age of four (Population Pyramids 2017a). The USA population, on the other hand, is more stable with slightly higher percentages in the 55-59 (6.9\%) and 20-30 (6.9\%) age groups, and 6.1\% of the population under age four (Population Pyramids 2017b). Greece has a larger population of older adults, with $6.8 \%$ of the population over the age of 80 , in comparison to only $3.7 \%$ of the USA population.

\section{Obesity}

A comparison of overweight and obesity status is complicated with diverse measurements and comparisons with statistics reported for the United States and Greece. Overweight and obesity have been defined based on Body Mass Index (BMI) for youth and adults. Those that are overweight or obese are at a higher risk for cardiovascular disease, type 2 diabetes, stroke, kidney disease, arthritis, and numerous cancers. (Singh et al. 2013, Lauby-Secretan et al. 2016). These conditions increase the health care burden among those affected by these conditions. Among adults, the set cut points are based on health risks. However the cut points for youth are statistical and based on a reference population (Ogden et al. 2015). These percentiles are utilized in assessing children by accounting for the dramatic changes in height, weight, and body composition throughout 
childhood with variations by sex (National Academies of Sciences, Engineering, and Medicine [National Academy of Sciences] 2016).

In the United States and Greece, a normal adult weight is defined as having a BMI of 18.5 - 24.9, overweight is 25 - $29.9 \mathrm{BMI}$, and obesity is a BMI of 30.0 or greater (ELSTAT 2016a, Ogden et al. 2015, Schiller et al. 2014). In the United States obesity has three classifications (National Academies of Sciences 2016). Obesity Class I is a 30.0 - 34.9 BMI, Class II is a 35.0 - 39.9 BMI, and Class III is equal to or greater than a BMI of 40. Obesity Class III is also known as extreme obesity. The 2014 US National Health and Nutrition Examination Survey (NHANES) found a crude estimate of overweight at 69.8\% which includes the subset of obesity. The crude rate ofobesity is estimated at $37.9 \%$, and extreme obesity at $6.4 \%$ among adults over 18 years (National Center for Health Statistics [NCHS] 2016). The incidence of obesity was higher among middle-aged adults (40 - 59) at $40.2 \%$ and 60 years and older at $37 \%$ (Ogden et al. 2015). There was no statistical difference between the middle-aged and elderly groups. Younger adults (20 - 39) had the lowest obesity rate at $32.3 \%$. However obesity did occur more often in women $(38.3 \%)$ than men $(34.3 \%)$ until age 60 or older. In the elderly group no difference was found between genders. Obesity rates did vary among ethnic groups in the USA with Non-Hispanic Blacks having the highest rate at $48.1 \%$ and Non-Hispanic Asians with the lowest rate at $11.7 \%$. The highest rate overall was among female Non-Hispanic Blacks (56.9\%). The incidence of overweight and obesity among adults in the United States was higher in 2014 than 2013; however the difference was not statistically significant (Schiller et al. 2014).

The Greek obesity rates for adults in 2014 utilizing the European Health Interview Survey were reported by ELSTAT (2016a). The age groups were different between the United States and Greece, starting with adults greater than 15 years in Greece as compared to 19 years in the US. The Greek crude rate for overweight was $39.2 \%$ without including obesity rates. The crude obesity rate was $17.0 \%$ among all adults over 15 years, considerably lower than the USA. The overweight rate for men was $47.6 \%$ and the obesity rate was $18.1 \%$ compared to $31.7 \%$ and $16.1 \%$ respectively in women. However no statistical difference was found between the genders. Unlike in the USA, overweight rates in Greece increased with age throughout the age groups. Young adults (15 - 24) had the lowest overweight rate for men at $29.4 \%$ and women at $6.7 \%$. In addition this age group also had the lowest obesity rate at $5.6 \%$ for men compared to $2.7 \%$ for women. The overweight rate for men increased to $54.6 \%(75+)$. The obesity rate for men peaked at $24.6 \%(55-64)$ as compared to $16.1 \%$ (75+). Females demonstrated the same overweight prevalence increase with age reaching $45.2 \%(75+)$. The female obesity rate peaked at $27.8 \%$ (65-74). The rates of obesity among adults in Greece were similar to those found in other southern European countries (Ogden et al. 2015). However $56.2 \%$ Greeks were either overweight or obese. In addition a relationship was found between education levels and obesity in Greece. Adults with low education had an obesity rate of $22.3 \%$, whereas those with a medium education level had 
$14.4 \%$ and high education levels had $13.4 \%$. So the obesity rates decreased as the education levels increased.

The term "obese" was not applied to children until 2007, when investigators noted a trend of increased BMI health related problems among children (National Academy of Sciences 2016). Within the United States for children from two to eighteen years, overweight and obesity is defined by their BMI's statistical relationship to the CDC growth chart reference population, based on age and gender. In the US, normal weight for children is within the 5th - 85th percentile, overweight is 85 th to 95 th percentile and obesity (Class I) is greater than the 95th percentile. Recently severe obesity was further defined for children in the US (Skinner et al. 2016). Class II obesity is greater than or equal to $120 \%$ of the 95th percentile or a BMI of 30 or greater. Class III obesity is $140 \%$ or more of the 95 th percentile or a BMI of 40 or greater.

Tzotzas et al. (2011) conducted a study of overweight and obese children in Greece. The researchers used the International Obesity Task Force (IOTF) criteria for obesity definitions. The IOTF defines overweight as ranging from the 90th percentile for the Dutch to the 95th percentile for the Britains (Cole et al. 2000). In Greece the principle is similar to the USA practice but the reference populations are related to the countries and ethnicity of various populations. Obesity is defined as equal to or greater than the 97th percentile for all groups. In the USA, the term obesity is not applied to children under two years of age (National Academy of Sciences 2016).

In the United States in 2014 for youth two to 19 years old, the overall rate of overweight was $33.4 \%$, Class I obesity was $17.4 \%$, Class II obesity was $6.3 \%$ and Class III obesity was $2.4 \%$ (Skinner et al. 2016). The overall prevalence of overweight and obesity in children is leveling off in the USA. However the incidence of Class II and Class III obesity is increasing. These severe obesity levels have associated higher cardio metabolic risks. The prevalence of overweight in preschool children $(2-5)$ was $25 \%$, school age $(6-11) 33.3 \%$, and adolescents (12-19) at $37.4 \%$. The obesity rate in preschool children (2-5) was 9.2\% school age (6-11) $17.9 \%$ and adolescents (12-19) at 20.9\%. Class II and Class III obesity also increased with age. Class II obesity ranged from $2.1 \%$ (25) to $9.5 \%(12-19)$ and Class III obesity went from $0.2 \%$ to $4.3 \%$. The pattern was the same for both genders.

Statistics regarding the rates of overweight and obesity for youth in Greece were difficult to locate, since this data was included in general European Union (EU) statistics or related to specific areas of Greece. Tzotzas et al. (2011) conducted a study of childhood obesity throughout Greece. The researchers found the prevalence of obesity in children six to 12 years to be $31.2 \%$ in boys and $26.5 \%$ in girls. There was a statistically significant difference between boys and girls with boys having a higher BMI. Similar to the USA, the prevalence of obesity increased with age in Greece.

There was no difference in the obesity prevalence based on residence in Greece. Even though the USA showed no change in the rate of obesity among youth over the previous years, Greece and other European countries have seen a continuing increase in obesity among youth. (The obesity rates in Greece were 
comparable to Spain, Italy, Portugal, and the United Kingdom.) Unfortunately the Greek obesity rates among youth continue to increase, approaching the rates in the United States.

Factors that may impact the Greek youth obesity rates are changes in diet, physical activity and health status, which have been influenced by western modernization and the economy. Currently Greek youth eat more saturated fats and lower carbohydrates. A lack of physical activity and an increase in sedentary behavior, such as watching television prevail. Tzotzas et al. (2011) also found a relationship between obesity in homes where the grandmother prepared meals and parents were indulgent, as demonstrated with overfeeding. The Greeks follow the Mediterranean Diet, but because of economic and sociological factors, their diets have changed to include more convenience foods that are higher in saturated fats and calories. This, along with lack of physical activity, may be contributing to the rising obesity rates.

\section{Physical Activity}

The increasing trend of obesity is a global epidemic that is influenced by physical activity levels. Nearly $26 \%$ of American adults do not engage in any leisure time physical activity. Many of those are on the low end of the economic scale, are less likely to have graduated from high school, and are over 65 (CDC 2017b). Almost 40\% of American children (grades 9-12) spend three or more hours playing computer games each day (Kim et al. 2016). As physical activity decreases, weight increases in male youth (age 12-15). As one ages, the likelihood of engaging in physical activity decreases where only $20 \%$ of the young individuals never exercised compared to $58 \%$ of those 55 years or older. Physical activity tracks over time from childhood to young adulthood (Fakhouri et al. 2014), which means that those who do not exercise now will more often be the ones who do not exercise in the future. Overall those who are physically inactive are more likely to be female, an ethnic minority, older, and with less education (CDC 2016a). However, early physical activity is associated with physical activity later in life (Hallal et al. 2006).

Maintaining a physically active lifestyle and reducing sitting time (Patel et al. 2010, Ploeg et al. 2012) is important contributor for enhancing life expectancy (Moore et al. 2012, Lee et al. 2012) and improving overall health. Physical activity is also associated with lower rates of heart disease, colon and breast cancer, type 2 diabetes, hypertension, depression, obesity, and osteoporosis (Janssen and Leblanc 2010, WHO 2010, United States Department of Health and Human Services [USDHHS] 2008). Those who are physically active are more likely to be productive at work, have fewer episodes of depression, have fewer missed workdays, and live with less functional limitations (USDHHS 2008). Economically those who are physically inactivehave higher health costs than their active counterparts. Inactive adults cost $\$ 1,313$ more per year than those who are active (Carlson et al. 2015).

Physical activity is often measured by self-report or interview surveillance systems. Surveys collect information on leisure time activities along with 
moderate to vigorous activities. Rates of physical activity across the USA are collected by the CDC through a random digit dialing survey using the Behavioral Risk Factor Surveillance System (BRFSS) or through sit down surveys such as the National Health Interview Survey (NHIS), the Youth Risk Behavior Survey (YRBS), and National Health and Nutrition Examination Survey (NHANES). In Greece similar health and physical activity data are collected through ELSTAT which is a component of The Hellenic Statistical System (ELSS). ELSS includes all agencies which are responsible for collecting statistical data. ELSTAT functions and remains outside of governmental control but under the regulation of the ELSS. ELSTAT collects all statistical information concerning Greece and distributes that information to Eurostat. ELSTAT is responsible for conducting the Hellenic Health Interview Survey (ELSTAT 2014). This survey is conducted every five years and collects demographic information along with the use of health services, prevalence of diseases, physical limitations, mental health, social support, and health determinants such as physical activity and nutritional intake.

The U.S. Department of Health and Human Services (USDHHS 2008) published the first national physical activity guidelines for Americans in 2008. The World Health Organization has published physical activity guidelines and global recommendations for specific age groups (WHO 2010). European Union (EU) Member States also have national Physical Activity Guidelines which assist in designing plans for supporting physical activity throughout the population (European Union Working Group "Sport and Health" 2008).

Making quantitative comparisons between the various physical activity guidelines from Greece and the USA is difficult since each group has different standards and emphasis. ELSTAT uses ages of 15 years and over where the USA standards are for children ages 6-17. ELSTAT differentiates information depending on the type of physical activity. For instance, physical activities are categorized according to the type of activity such as walking, bicycling, dancing, or swimming where the USA standards provide overall recommendations of time spent at various intensity of effort.

Physical activity guidelines for the general USA public recommend at least 150 minutes of moderate-intense exercise every week (USDHHS 2008). Children and adolescents (age 6-17) are advised to engage in 60 minutes of physical activity every day. Resistance training is also encouraged where both the USA and European recommendations include muscle strengthening activities at least two days each week. There are no specific guidelines on how long a resistance exercise session should occur. Suggestions of $8-10$ repetitions of a weight would help improve muscle strength. A beneficial muscle strengthening exercise would include one in which it would be difficult to repeat another session. These guidelines also recommend that people minimize sitting or sedentary time. The physical activity recommendations for all age groups in the European countries (WHO 2010) directly reflect those of the USDHHS (2008).

According to the US 2008 Physical Activity Guidelines (USDHHS 2008), only about one in five adults meet the recommended activity level of 150 minutes per week and almost half (48\%) of adults engage in no leisure time activity. Walking is being promoted by the US Surgeon General as a means of increasing 
physical activity and there are signs that walking is increasing in some populations (USDHHS 2015a). Those with more education and those living above the poverty line are more likely to meet the guidelines. Guidelines are more likely to be met in the USA if one is a non-Hispanic white, male and younger. In addition those living in the southern states are less likely to meet the guidelines. Less than three out of 10 high school students meet the recommended 60 minutes of physical activity per day (Ussery et al. 2017). Physical inactivity is associated with numerous adverse health conditions (Lee et al. 2012). Global declines in children's physical fitness have been noted over the past few years (Institute of Medicine [IOM] 2013, Kim et al. 2016) as the hours spent watching television and computer screens has increased (Fakhouri et al. 2013, Rideout et al. 2010).

In Greece, according to Eurostatas of 2017 up to $74.1 \%$ of those living in Greece do not get any aerobic physical activity. However, $84.6 \%$ of adults in Greece did meet the recommended physical activity requirements of 150 minutes per week. Across European countries, 59\% of the population report never or seldom engaging in physical activity or sport (European Commission 2014). A little over half (54\%) of Europeans do not engage in any vigorous activity and two-thirds spend between 2.5 and 8.5 hours sitting. For close to half of those surveyed (42\%), a lack of time was the main reason for not engaging in physical activity even though three-fourths agreed that there were fitness centers in their local area.

Populations at risk for physical inactivity include older individuals along with women, ethnic minorities, those with less education, those who are overweight or obese, those who are disabled and those with mostly sedentary professions (such as truck drivers). Other risk factors for physical inactivity include personal concern for safety, fear of injury, cost of getting to an exercise facility, and having low socioeconomic status (Watson et al. 2016). These guidelines encourage individuals to take steps to minimize risk of injury and promote safe access to exercise facilities. Lack of information about the benefits of exercise and physical activity may be a cause of inactivity.

Diet

Greeks typically follow the Mediterranean Diet, which is rich in nutrients and is known for its health benefits. This cuisine is based on a high consumption of plant foods with a reduced intake of animal based protein. For instance, the diet is bountiful in fruits, vegetables, whole grains, olive oil, and herbs and spices. At least three servings of fruit, six servings of vegetables, and eight servings of non-refined grains should be consumed daily. On this diet, two servings of dairy products should be consumed per day and three servings of eggs per week. Nuts and seeds are consumed weekly ranging from three to four servings. Chicken and fish are consumed in moderate servings throughout the week ranging from four to six servings. Red meats are consumed the least with four servings a month. In addition, wine is consumed in moderation and sweets are eaten occasionally with a maximum of three servings a week. These guidelines are based on the Mediterranean Food Pyramid. It highlights the recommended 
portions and frequency of foods to be consumed as well as the guidelines of the Food and Agriculture Organization of the United Nations (The Mediterranean Diet Organization 2014, Food and Agriculture Organization of the United Nations 2017). Refer to Figure 1 for an image of the Mediterranean Food Pyramid.

Figure 1. Image of the Mediterranean Food Pyramid

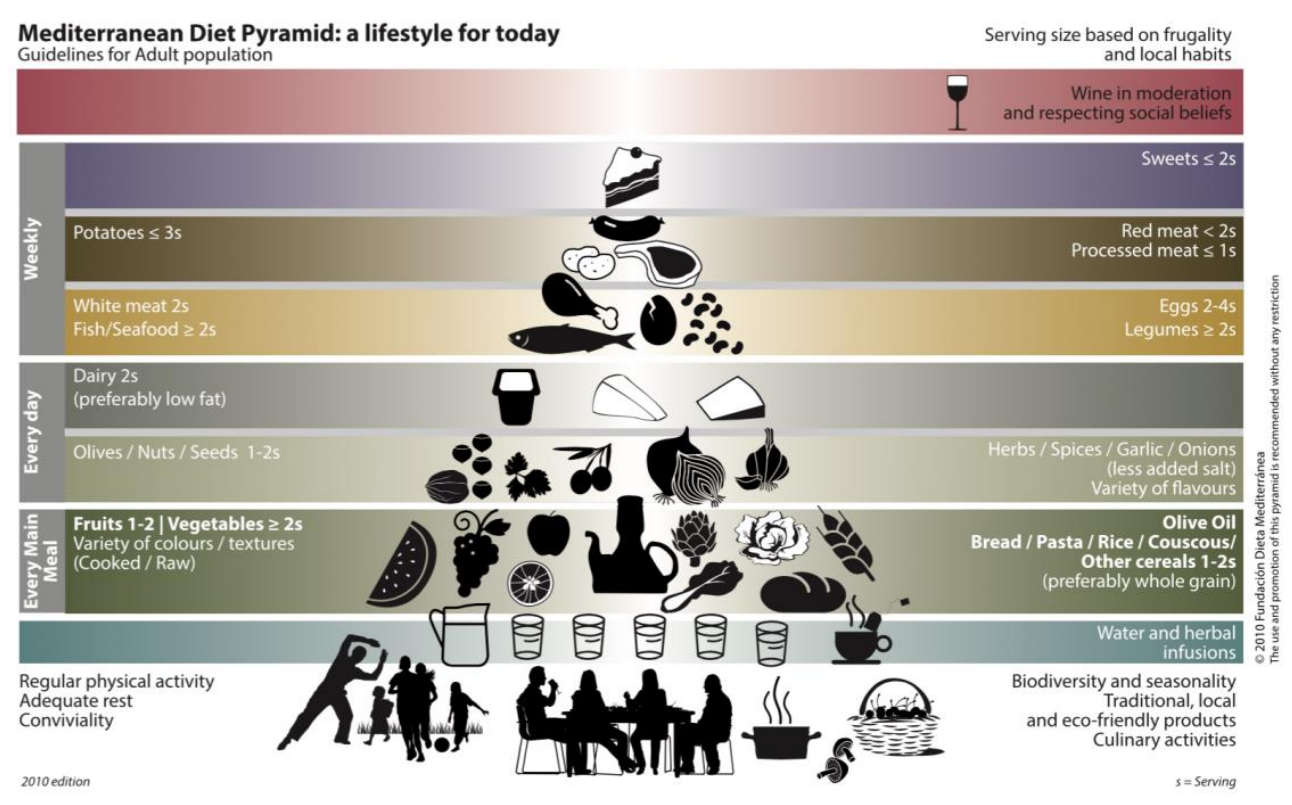

Source: The Mediterranean Diet Organization 2014

This pattern of eating originated from cultures among the countries surrounding the Mediterranean Sea such as Greece, Spain, Italy, and Morocco (Bach-Faig et al. 2011). The Mediterranean diet also includes other cultural aspects with meals. For instance, cooking is seen as an important activity not meant to be rushed but instead spent with loved ones in a relaxed atmosphere. In addition, meals are part of a social setting that gives a sense of community as food and support is shared throughout the meal. Seasonality also has an impact on which foods are eaten with preference given to foods in season, minimally processed, and fresh. (The Mediterranean Diet Organization 2014).

As previously mentioned, adopting the Mediterranean diet can help improve health. Properties of the Mediterranean diet assist in the prevention of chronic diseases and mental deterioration, as well as help with weight loss (Corliss 2015). Consuming the Mediterranean diet has been associated with a reduction in undesirable health conditions such as peripheral artery disease, heart attacks, and strokes (Pendick 2014). According to Panagiotakos et al. (2006), high adherence to the Mediterranean diet was linked to a 51\% lower risk of becoming obese compared to non-adherence.In addition, in a cohort study by Scarmeas et al. (2006), high adherence to the Mediterranean diet was associated with a 39$40 \%$ decrease in developing Alzheimer's disease in comparison to those with low adherence to the Mediterranean diet who were 9-10\% less likely to develop 
Alzheimer's disease. Coupled with physical activity, the Mediterranean diet can further improve one's health.

In contrast, Americans are advised to follow the United States Department of Agriculture's MyPlate and the USA Dietary Guidelines. The guidelines assist Americans with adhering to a healthy diet by following five main concepts: "1.) follow a healthy eating pattern across the lifespan, 2.) focus on variety, nutrient density, and amount, 3.) limit calories from added sugars and saturated fats and reduce sodium intake, 4.) shift to healthier food and beverage choices, and 5.) support healthy eating patterns for all" (USDHHS and U.S. Department of Agriculture [USDA] 2015).

From 1995 until 2005, the Dietary Guidelines used the Food Guide Pyramid to serve as a visual resource to help Americans adhere to the national dietary standards (USDHHS and USDA 2013). Although the Food Guide Pyramid has since been replaced with a different model, it was similar to the Mediterranean Diet Pyramid. For instance, both pyramids had a comparable layout and consisted of foods with high serving amounts at the base of the pyramid and foods with low serving amounts such as sweets, at the top of the model. Refer to Figure 2 for an image of the Food Guide Pyramid (USDHHS and USDA 2000).

Figure 2. Image of the Food Guide Pyramid

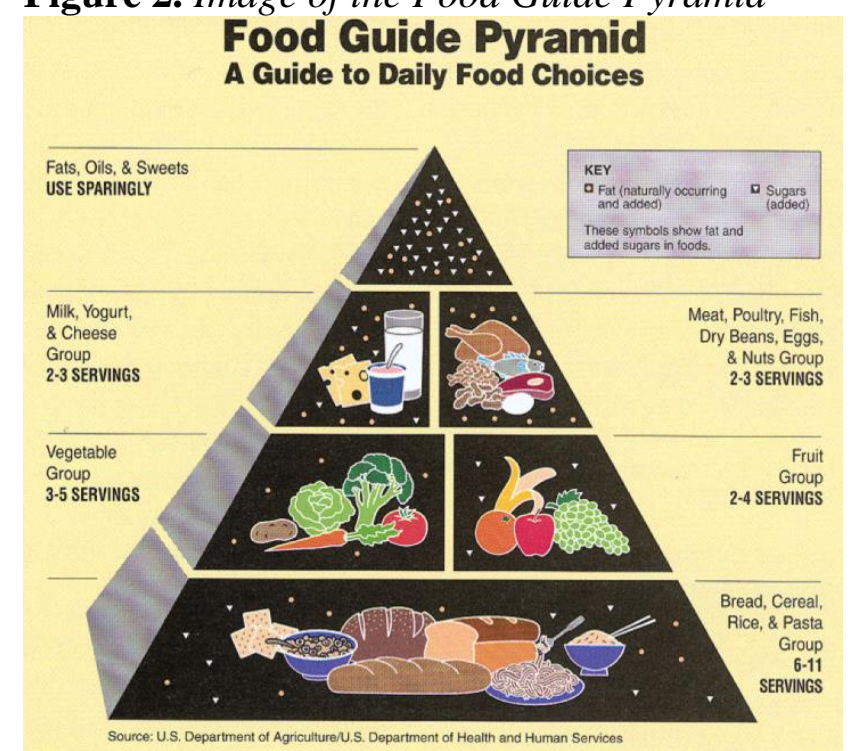

Source: U.S. Department of Health and Human Services and U.S. Department of Agriculture 2000

In 2005 the Food Guide Pyramid was replaced with MyPyramid. The updated pyramid included physical activity in its design as did the Mediterranean Diet Pyramid. In addition, MyPyramid was split into colored bands of various widths to represent the different food groups. The smaller the width of the band, the lesser amount of servings one should incorporate from that food group (Corbin et al. 2006). See Figure 3 for an illustration of MyPyramid. 
Figure 3. Image of MyPyramid

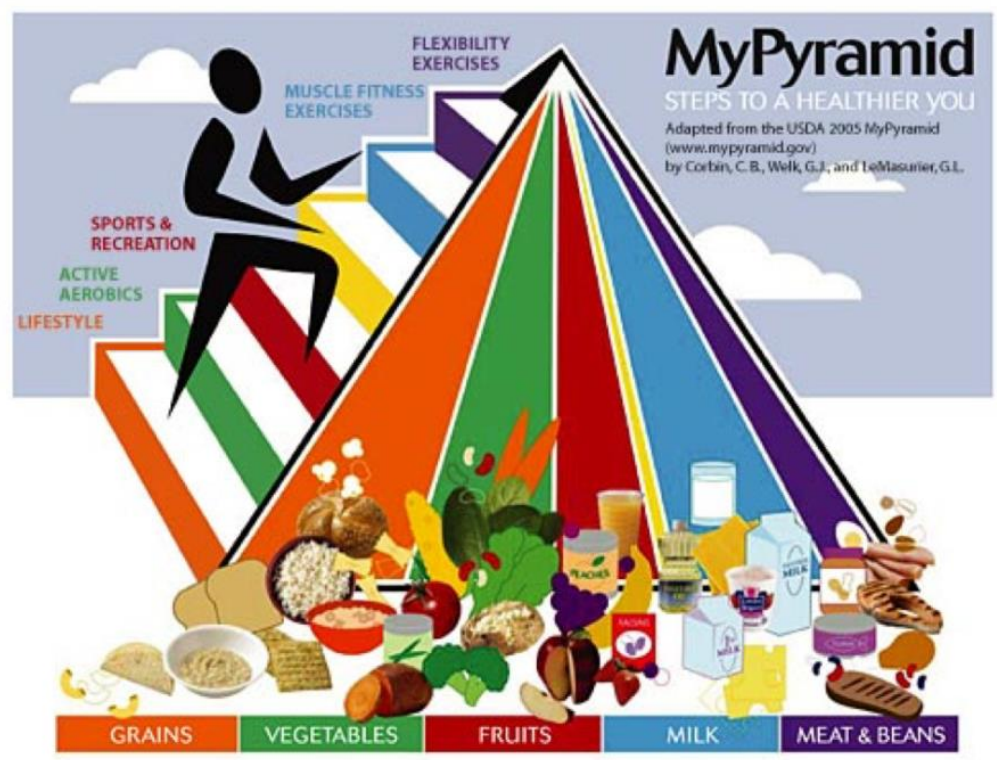

Source: Corbin et al. 2006

However, in 2011 the USA shifted from MyPyramid to MyPlate. This new visual tool is illustrated as a plate with sections divided into the five food groups (grains, vegetables, fruit, dairy, and protein). The food group sections represent the adequate portion sizes for each food group during a meal. Although MyPlate seems to lack detail visually, ChooseMyPlate.gov provides in depth detail regarding descriptions of each food group, serving sizes, and physical activity. Refer to Figure 4 for a visual representation of MyPlate (USDA 2017).

Figure 4. Image of MyPlate

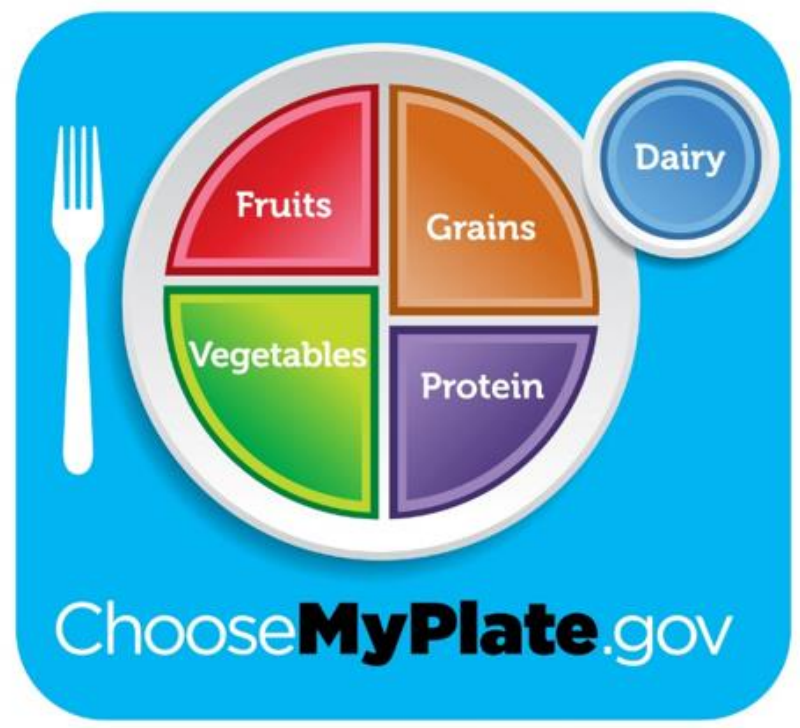

Source: U.S. Department of Agriculture 2017 
Greeks tend to consume more fruits and vegetables than Americans. In $2014,44.0 \%$ of Greeks (15 years and older) ate one serving of fruit daily and $37.0 \%$ consumed two servings of fruit daily (ELSTAT 2016a). In contrast, $60.3 \%$ of American adults in 2015 consumed at least one serving of fruit per day (CDC 2015a). In regard to vegetable consumption, $64.1 \%$ of Greeks ate one serving of vegetables daily and $30.6 \%$ consumed two servings daily (ELSTAT 2016a). However, $77.9 \%$ of Americans consumed at least one serving of vegetables per day (CDC 2015a).

Overall, Americans consume large amounts of high-fat, calorie-laden fast foods which tend to be convenient and inexpensive. A 2006 survey conducted by Rutgers University found that Americans were 17 times more likely to consume fast food for convenience. In addition, $38 \%$ of those surveyed reported eating out once a week and $25 \%$ ate food away from home every two to three days during the week. Only $1 \%$ stated that they never eat out (USDA 2006). Furthermore, a study conducted by Escoto et al. (2012) found that Americans who work more hours during the week were less likely to eat a healthful diet. For example, $43.6 \%$ of males and $37.3 \%$ of females who worked 40 hours or more during the week reported that they were "too busy to eat healthy" compared to men $(29.9 \%)$ and women $(36 \%)$ who worked 1 to 19 hours during the week. Also, $38.6 \%$ of males and $42 \%$ of females who worked at least 40 hours reported difficulty in finding time to sit down and eat a meal. However, only $28.3 \%$ of men and $32.6 \%$ of women who worked between one to 19 hours throughout the week identified that problem. In addition, about $60 \%$ of males and females who worked 40 hours or more during the week were more likely to "eat on the run" compared to those who worked fewer hours.

In comparing number of hours worked, Greeks worked more hours $(2,042$ hours) in 2015 than Americans (1,790 hours). Greece also ranked fourth among thirty-eight other countries regarding the average yearly hours worked per worker in 2015 (Organisation for Economic Co-operation and Development [OECD] 2017). Furthermore, ELSTAT (2016b) reported that Greeks spend an average of about six hours during the day working or participating in other employment related activities such as searching for jobs or engaging in work brought home. However, no time was accounted for in regards to taking a lunch break during work hours. In addition, Greeks spend about four hours of their day eating, one hour for food management, and forty-five minutes for preparing, cooking, and preserving food. Therefore, food and meals are a priority for Greeks despite the high work hours.

\section{Smoking and Tobacco Use}

Tobacco use has been identified as one of the most preventable causes of disease and death (WHO 2009, USDHHS 2015b). Worldwide, there are six million annual deaths attributable to all forms of tobacco use, with nearly one million deaths occurring from exposure to secondhand smoke (WHO 2017). The overall prevalence of smoking (40\%) in Greece is twice that of the USA (19\%), and in both nations males smoke more than females. In Greece, 39.4\% 
of men aged 15 years and over, and $26.4 \%$ women aged 15 years and over smoke either occasionally or on a daily basis (ELSTAT 2016a). In the USA, $16.7 \%$ of adult men (18 years and older) and $13.6 \%$ of adult women smoke (CDC 2016a).

American youth used electronic cigarettes more than regular cigarettes, unlike in Greece where more youth smoke regular cigarettes. The use of tobacco most often begins in adolescence or younger (USDHHS 2014). Among high school students in the USA (grade 9-12 or ages $15+$ ), $25 \%$ used any form of tobacco, including e-cigarettes. Males (30\%) were more likely to use any type of tobacco as compared to females (20\%). The most prevalent type of tobacco product used by youth in the USA was electronic cigarettes (16\%) followed by cigarettes (9\%) (CDC 2016b). In the USA, $2 \%$ of middle school youth (13-15 years) reported smoking in the past 30 days. According to the 2013 Global Youth Tobacco Survey results (2013), overall 15\% of Greek youth ages 13-15 smoked, $17 \%$ of males and 13\% of females (WHO 2015). In addition, $42 \%$ of youth started smoking between the ages of 15-18 (ELSTAT 2016a). In the USA, most youth also initiated smoking in adolescence and before age 18 (USDHHS 2014).

In regards to secondhand smoke, $60 \%$ of Greek youth ages 13-15 experience exposure (WHO 2015). About 56\% of Greeks 15 and over are exposed to secondhand smoke in bars, cafes, tavernas or restaurants, and one third in their homes (ELSTAT 2016a). About 40\% of American youth, ages 3-11, are exposed regularly to secondhand smoke, with prevalence higher among non-white children (CDC 2015b). In the USA, exposure to secondhand smoke has decreased because of indoor bans on smoking, a decline in smoking rates and increased social unacceptability of smoking. Among non-smoking Americans, indications of exposure to secondhand smoke, cotinine levels, have declined from $90 \%$ in 1988 (CDC 2010) to 25\% in 2012 (CDC 2015b).

In September of 2010, Greek legislators passed banning smoking in workplaces, transportation stations, taxis, airplanes, and buses. The ban also included public places such as restaurants and night clubs. Despite the bans, there seems to be little compliance with the laws and penalty enforcement (Greek Reporter 2013). There is debate about the impact of a strictly enforced ban on the tax base in Greece as compared to the savings in terms of less disease and health care costs.

In 2016, Greece banned the use of electronic cigarettes in public places (Cable News Network [CNN] Greece 2016). Direct messages about money saved for retirement by not smoking have been publicized (The National Herald 2016). Further, public health initiatives have been suggested which would target youth to prevent them from smoking, despite their being able to purchase cigarettes at any age.

\section{Sleep Patterns}

Sleep is essential for good health. Lack of sleep can affect both physical and mental health (National Institute of Neurological Disorders and Stroke 
[NINDS] 2014). Individuals sleeping less than 7 hours a night are at an increased risk of diseases such as high blood pressure, stroke, heart disease and diabetes (Liu et al. 2013). In the USA, 40 million people have long-term sleep disorders while an additional 20 million experience acute sleeping problems (NINDS 2014). About $25 \%$ of the USA population report not getting enough sleep on occasion while 10\% have chronic problems with sleep (CDC 2015c).

In Greece, the average amount of time for sleep is eight hours and 23 minutes per night, including daytime napping, for adults 20-74 (ELSTAT 2016b). For Americans 25-54 with children, the average time sleeping is 7.8 hours (U.S. Bureau of Labor Statistics 2016). However, in the US for ages 15 and over, the average amount of time sleeping is 8.8 hours per day.

In some regions of Greece, midday napping is still practiced, providing numerous health benefits in addition to lessening the likelihood of death. Yet few working Americans have the opportunity to nap during the work day. Napping during the day provides various health benefits including increased alertness and productivity (Mayo Clinic 2015). For the Greeks, napping in the afternoon is done to escape the heat, and to rest before returning to work in the evening. In a study of Greek men, those who napped for at least 30 minutes a day were significantly less likely to die from heart attacks (Naska et al. 2007).

Individuals in both countries with a high body mass index (BMI) may experience sleep disorders. Being overweight is one risk factor for obstructive sleep apnea. Difficulties in breathing associated with sleep apnea may be attributed to extra fat in the neck area and/or inflammation resulting from fat in that area and/or throughout the body (National Institute of Diabetes and Digestive and Kidney Diseases [NIDDK] 2012).

\section{Blue Zone Comparisons}

The term Blue Zones refers to specific regions where people tend to live longer than the rest of the global population, with a larger portion of people still active beyond the age of 90 . The island of Ikaria, located in Greece, is a blue zone. People of Ikaria have environmental and lifestyle factors conducive to their longevity. This includes having rich social lives, a plant-based diet, daily physical activity, and lower rates of smoking. One possible factor is the mountainous terrain, which Ikaria shares in common with other blue zones, such as Ogliastra, in Sardinia, Italy, and the Nicoya peninsula, in Costa Rica. Another common factor these regions share is a lower socio-economic status than neighboring regions (Poulain et al. 2013).

The Mediterranean Islands (MEDIS) Study, conducted from 2005-2007, collected data on those over 80 and 90 years old in eight Mediterranean islands (other than Ikaria). A more recent study compared those results to a sample of the oldest old in Ikaria. Over $60 \%$ of study participants in Ikaria reported moderate physical activity, and the smoking rate was low in this group (17\% of men, $7 \%$ of women) (Panagiotakos et al. 2011). Participants reported stricter adherence to the traditional Mediterranean diet than those in the MEDIS Study. In addition, $84 \%$ of men and $67 \%$ of women took a daily nap; those who took a daily nap 
had lower depression scores than those who did not. Also, many of them had another person living with them--usually a spouse or relative--helping to ward off loneliness and depression. Among the oldest old in Ikaria, 41.4\% of men and $49.5 \%$ of women reported their financial status as low (Panagiotakos et al. 2011).

In Loma Linda, California, a Blue Zone located in the United States, people live an average of ten years longer than in the rest of the country. The community is home to the Loma Linda University Medical School, which has produced many research studies in health and wellness. The city enforces a smoking ban on its citizens (City of Loma Linda n.d.). Many of Loma Linda's population of 23,000 belong to the Seventh-day Adventist community, and their religious practices may influence their longevity. This group of conservative Protestants evangelize through their health practices, treating their bodies like a temple (Buettner 2012).

Seventh-day Adventists honor the Sabbath by resting for an entire day each week. Beginning at sundown on Fridays, they halt any activities that could be considered work, including grocery shopping and television viewing. They do not resume activities until Saturday at sunset. This provides relief from stress as well as time for community and social support. They also abstain from coffee and alcohol, and follow a biblical vegan diet, including plenty of water and nuts, which are both associated with a decrease in cardiovascular events (Buettner and Skemp 2016, Buettner 2012). Americans who strictly follow the Adventist diet have lower rates of heart disease and diabetes than the rest of the country. Drinking only water and eating only a plant-based diet, they avoid sugar-laden, salty, and processed foods (Buettner 2012).

The Adventist Health Study 2, a cohort study that followed over 73,000 Seventh-day Adventist men and women in North America, analyzed the effects of the Adventist diet on human health (Orlich et al. 2013). There were significant correlations between a vegetarian diet and lower mortality from cardiovascular disease, noncancerous noncardiovascular causes, renal disease, and endocrine problems, especially in men. Overall mortality was lower in vegetarians than nonvegetarians (Orlich et al. 2013). The plant-based diet of those in Loma Linda may be a key contributing factor to their longevity. Furthermore, Adventists tend to eat a large breakfast, a medium-sized lunch, and a light dinner, so their calorie intake is balanced with their activity levels throughout the day (Buettner 2012).

\section{Public Health and Health Promotion}

Public health is the art and science of preventing disease, promoting health, and prolonging life of populations (CDC Foundation 2017). In both countries, the need for public health including health education and promotion is apparent. Obesity rates are increasing while physical activity is on the decline, especially among older individuals. As stated previously, nutritional intake in both countries is moving toward consumption of foods that are less nutritious. Behavior change could be facilitated by those trained in public health and health promotion.

The USA supports a vast public health network including public health agencies and universities offering degrees in public health. The USA has over 
180 accredited schools of public health (Council on Education for Public Health 2017). In Greece such opportunities to study and practice public health are limited. The University of Athens (n.d.) houses the National School of Public Health (n.d.) (formerly the Athens School of Hygiene) and is one of the oldest schools of public health in Europe. The National School of Public Health (NSPH) trains graduate students and other professionals in biostatistics, epidemiology, infectious and noncommunicable disease prevention, social research, environmental health, and health services management. The NSPH also conducts research and consults with the Hellenic Center for Disease Control and Prevention (HCDCP), the European Center for Disease Control (ECDC), WHO, and other public health organizations.

Individuals earning degrees in public health, health education, and health promotion are trained in promoting the health of others through various means, one of which is social marketing. Social marketing is the use of marketing theories and practices to increase awareness of health issues, and to promote or reduce certain health behaviors (CDC 2017c). Social marketing of predominant health issues is a commonly used strategy in the USA but rare in Greece. For example, social marketing in the USA uses proven strategies to motivate individuals to be physically active, stop smoking, and reduce their weight. In Greece, the practice of social marketing and health promotion is being considered, especially to help reduce health care costs (Papadopoulous, personal communication June 21, 2016). Risk factor identification and reduction are key elements in reducing the Greek health care burden. Proven effective programs in the USA address tobacco use, physical activity (Andrews et al. 2011), obesity (Heymsfield and Wadden 2017), dietary risks and mental health issues such as depression. Similar programs should also be effective in Greece.

\section{Discussion}

This study began in Greece in 2016, as a part of a Health and Wellness Study Abroad Program for undergraduates and graduates from a university in southeast Louisiana, USA. The researchers and students conducted interviews of Greek health care professionals including doctors, nurses, pharmacists, massage therapists, physiotherapists and other health professionals. In addition, students and faculty visited the Greek Ministry of Health and the Greek Council on Refugees to gain further knowledge about the health and wellbeing of individuals living in Greece.

Although salient information was gleaned through these interviews and by observations, more face-to-face meetings with Greek people, especially older adults, would have been helpful in contrasting health behaviors of Greeks and Americans. Finally, many credible, published sources of information were used in the completion of this study. Main sources included surveillance systems from the USA's CDC and Greece's ELSTAT. These latter sources were vital in providing current information about each country, since such data are often difficult and expensive to collect first hand. However, data collection differences 
in Greece and the USA as well as categorical groupings, like age groups, made it challenging when comparing various health behaviors or health status. In addition, some information may have been missed because of language barriers.

Contrasting healthful behaviors of individuals in Greece and the USA is beneficial to those seeking to improve their own personal health and the health of others. Although the diet of some Greeks may be changing, the Mediterranean diet with its abundance of fruits and vegetables and limited meats is still an important factor in promoting both mental and physical health. Obesity rates in Greece and the USA are also increasing; however the USA has more public health initiatives addressing this growing problem and the lack of physical activity among its citizens.

Greece has a higher prevalence of smoking than the USA and has recently initiated smoking bans in certain public areas; smoking bans have been in effect in the USA for longer, reducing both exposure to secondhand smoke and associated chronic diseases and deaths. However, in the USA the use of electronic cigarettes is an emerging negative health issue, especially among youth.

In areas labeled as "Blue Zones" in both the USA (Loma Linda) and in Greece (the island of Ikaria), individuals practice similar health behaviors which may impact longevity; some of these behaviors include consuming a plant-based diet, engaging in religious and social activities, taking part in daily physical activity as well as not using or reducing use of tobacco products. Both countries have recognized the need for public health practices and health promotion for the prevention of disease and disability, and to decrease health care costs. Greece and the USA have identified primary health care as a vital component in this movement as well as an increased need for social marketing of healthy behaviors, health policies, and health promotion practices (Papadopoulous, personal communication June 21, 2016, CDC 2017c).

\section{Conclusions}

Our study provided key information concerning the health behaviors and status of Greeks and Americans. To further knowledge, additional studies should be conducted to contrast the health practices of citizens and public health policy in other countries. In turn, the identification of health behaviors, health policies and other factors vital to optimal health may increase health promotion efforts worldwide thus impacting quality of life and longevity.

\section{References}

Andrews R C, Cooper A R, Montgomery A A, Norcross J, Peters T J, Sharp D J, Jackson N and Dayan C M (2011) Diet or diet plus physical activity versus usual care in patients with newly diagnosed type 2 diabetes: the Early ACTID randomised controlled trial. Lancet.378, 129-39. 
Bach-Faig A, Berry E, Lairon D, Reguant J, Trichopoulou A, Dernini S and SerraMajem L (2011) Mediterranean diet pyramid today. Science and Cultural Updates. Public Health Nutr. 14, 12A, 2274-2284. DOI= 10.1017/S13689800 11002515

Buettner D (2012) The blue zones: 9 lessons for living longer from the people who've lived the longest. Washington, D.C.: National Geographic Books.

Buettner D and Skemp, S. (2016) Blue zones lessons from the world's longest lived. Am J Lifestyle Med. 10, 5, 318-321. DOI=1559827616637066.

Cable News Network (CNN) (2016) Voted the ban on electronic cigarettes. (Greece, Sept. 8, 2016).

Carlson S A, Fulton J E, Pratt M, Yang A and Adams K (2015) Inadequate physical activity and health care expenditures in the United States. Prog Cardiovasc Dis. 57, 4: 315-323.

Centers for Disease Control and Prevention (2010) Vital signs: nonsmokers' exposure to secondhand smoke-United States, 1999-2008. MMWR 2010. 59, 35, 1141-6.

Centers for Disease Control and Prevention (2014) Deaths and mortality. Retrieved from http://www.cdc.gov/nchs/fastats/deaths.htm.

Centers for Disease Control and Prevention (2015a) Behavioral Risk Factor Surveillance System (BRFSS) prevalence and trends data: fruits and vegetables. Retrieved from https://nccd.cdc.gov/BRFSSPrevalence/rdPage.aspx?rdReport=DPH_BRFSS.Ex ploreByLocation $\&$ rdProcessAction $=\&$ SaveFileGenerated $=1 \&$ irbLocationType $=S$ tates\&islLocation=98\&islClass $=$ CLASS06\&islTopic $=$ Topic60\&islYear=2015\&h idLocationType $=$ States $\&$ hidLocation $=98 \&$ hidClass $=$ CLASS06\&hidTopic $=$ Topic 60\&hidTopicName=Vegetable+Consumption\&hidYear=2015\&irbShowFootnote $\mathrm{s}=$ Show\&iclIndicators_rdExpandedCollapsedHistory=\&iclIndicators=_VEGLT1 \&hidPreviouslySelectedIndicators $=\&$ DashboardColumnCount $=2 \&$ rdShowEleme ntHistory $=\& \mathrm{go}=\mathrm{GO} \& \mathrm{rdScrollX}=0 \& \mathrm{rdScroll} \mathrm{Y}=0 \& \mathrm{rdRnd}=14636$

Centers for Disease Control and Prevention (2015b) Vital signs: disparities in nonsmokers' exposure to secondhand smoke-United States, 1999-2012. MMWR 2015. 64, 4: $103-108$.

Centers for Disease Control and Prevention (2015c) Sleep and sleep disorders. Retrieved from https://www.cdc.gov/sleep/index.html

Centers for Disease Control and Prevention (2016a) Current cigarette smoking among adults in the United States. Retrieved from https://www.cdc.gov/tobacco/data_st atistics/fact_sheets/adult_data/cig_smoking/index.hm

Centers for Disease Control and Prevention (2016b) Tobacco use among middle and high school students-United States, 2011-2015. MMWR 2016. 65, 14: 361-367.

Centers for Disease Control and Prevention (2017a) Leading causes of death. Retrieved from https://www.cdc.gov/nchs/fastats/leading-causes-of-death.htm

Centers for Disease Control and Prevention (2017b) Data, trends and maps. National Center for Chronic Disease Prevention and Health Promotion, Division of Nutrition, Physical Activity, and Obesity. Retrieved from https://www.cdc.gov/nccdphp/dn pao/data-trends-maps/index.html.

Centers for Disease Control and Prevention (2017c) Effective interventions: social marketing. Retrieved from https://effectiveinterventions.cdc.gov/en/HighImpact Prevention/SocialMarketing.aspx

Centers for Disease Control Foundation (2017) What is public health? Retrieved from http://www.cdcfoundation.org/content/what-public-health

Central Intelligence Agency (2016) The world factbook. Retrieved from https://www. cia.gov/library/publications/the-world-factbook/geos/gr.html and https://www.ci a.gov/library/publications/resources/the-world-factbook/geos/us.html 
City of Loma Linda. n.d.. Our city. Retrieved from http://www.lomalinda-ca.gov/asp/ Site/OurCity/Statistics/index.asp

Cole T J, Bellizzi M C, Flegal K M and Dietz W H (2000) Establishing a standard definition for childhood overweight and obesity worldwide: international survey. Br Med J. 320, 1240 - 1246. DOI=10.1136/bmj.320.7244.1240.

Corbin C, Welk G, Corbin W and Welk K (2006) Concepts of fitness and wellness: A comprehensive lifestyle approach: sixth edition. Retrieved from http://www.mh he.com/socscience/hhp/otw/fit_well/web16/\#_Toc103145897

Corliss J (2015) Mediterranean diet may help counteract age-related declines in memory and thinking skills. Retrieved from http://www.health.harvard.edu/blog/mediterranea n-diet-may-help-counteract-age-related-declines-in-memory-and-thinking-skills-20 1505138007

Council on Education in Public Health (CEPH) (2017) Accredited schools and programs: schools of public health. Retrieved from: https://ceph.org/accredited/

Escoto K, Laska M, Larson N, Neumark-Sztainer D and Hannan P (2012) Work hours and perceived time barriers to healthful eating among young adults. Am J Health Behav. 36, 6, 786-796. Retrieved from https://www.ncbi.nlm.nih.gov/pmc/artic les/PMC3464955/pdf/nihms373265.pdf

European Commission, Directorate-General for Education and Culture (2014) Sport and physical activity report. Special eurobarometer 412. Brussels: European Commission Directorate-General for Education and Culture. Retrieved from http:// www.euro.who.int/_data/assets/pdf_file/0020/288110/GREECE-Physical-ActivityFactsheet.pdf. DOI= 10.2766/73002.

European Union Working Group "Sport and Health." (2008) Physical activity guidelines: recommended policy actions in support of health-enhancing physical activity (2008). Retrieved from http://ec.europa.eu/assets/eac/sport/library/policy_docu ments/eu-physical-activity-guidelines-2008_en.pdf

Eurostat. n.d. European health interview survey (EHIS). Retrieved from http://ec.euro pa.eu/eurostat/web/microdata/european-health-interview-survey

Eurostat (2016) European health interview survey: almost 1 adult in 6 in the European Union is considered obese. Share of obesity increases with age and decreases with educational level. News Release, No. 203. Retrieved from http://ec.europa.e u/eurostat/documents/2995521/7700898/3-20102016-BP-EN.pdf/c26b037b-d5f3 $-4 \mathrm{c} 05-89 \mathrm{c} 1-00 \mathrm{bf0b} 98 \mathrm{~d} 646$ June 13, 2017.

Eurostat (2017) Time spent on health-enhancing (non-work-related) aerobic physical activity by sex, age and educational attainment level. [Data file]. Retrieved from http://ec.europa.eu/eurostat/data/database.

Fakhouri T H, Hughes J P, Brody D J, Kit B K and Ogden C L (2013) Physical activity and screen-time viewing among elementary school-aged children in the United States from 2009-2010. JAMA Pediatr. 167, 3: 223-229

Fakhouri T H, Hughes J P, Burt V L, Song M K, Fulton J E and Ogden C L (2014) Physical activity in U.S. youth aged 12-15 years, 2012. National Center for Health Statistics (NCHS) data brief, no 141. Hyattsville, MD: National Center for Health Statistics.

Food and Agriculture Organization of the United Nations (2017) Food-based dietary guidelines. Retrieved from http://www.fao.org/nutrition/education/food-based-die tary-guidelines/regions/countries/greece/en/

GBD 2015 Tobacco Collaborators (2017) Smoking prevalence and attributable disease burden in 195 countries and territories, 1990-2015: a systematic analysis from the global burden of disease study 2015. Lancet. 389, 1885-906. DOI= http://dx.doi. org/10.1016/S0140-6736(17)30819-X 
Greek Reporter (2013) Greece says smoking ban to start. Retrieved from http://gree ce.greekreporter.com/2013/02/23/greece-says-smoking-ban-to-start/

Hallal P C, Victora C G, Azevedo M R and Wells J C (2006) Adolescent physical activity and health: A systematic review. Sports Medicine. 36, 12: 1019-1030.

Hellenic Statistical Authority (ELSTAT) (2014) Deaths-2014. Retrieved from http:// www.statistics.gr/en/statistics/-/publication/SPO09/-.

Hellenic Statistical Authority (ELSTAT) (2015) Causes of death: 2013. Retrieved from http://www.statistics.gr/en/statistics/-/publication/SPO12/2013.

Hellenic Statistical Authority (ELSTAT) (2016a) Health determinants: year 2014 http://www.statistics.gr/en/statistics?p_p_id=documents_WAR_publicationsportl et_INSTANCE_qDQ8fBKKo4IN\&p_p_lifecycle=2\&p_p_state=normal\&p_p_m ode=view\&p_p_cacheability $=$ cacheLevelPage\&p_p_col_id=column $-2 \& p \_p \_c o l$ _count=4\&p_p_col_pos=1\&_documents_WAR_publicationsportlet_INSTANCE _qDQ8fBKKo41N_javax.faces.resource=document\&_documents_WAR_publicat ionsportlet_INSTANCE_qDQ8fBKKo4IN_ln=downloadResources\&_documents _WAR_publicationsportlet_INSTANCE_qDQ8fBKKo4lN_documentID=223073 \&_documents_WAR_publicationsportlet_INSTANCE_qDQ8fBKKo4IN_locale= en

Hellenic Statistical Authority (ELSTAT) (2016b) Time use survey 2013-2014. Retrieved from http://www.statistics.gr/en/statistics/-/publication/SFA30/-

Heymsfield S B and Wadden T A (2017) Mechanism, pathophysiology, and management of obesity. N Engl J Med. 376: 254-266.

Institute of Medicine (IOM) (2013) Educating the student body: Taking physical activity and physical education to school. Washington, DC: The National Academies Press.

Janssen I and Leblanc AG (2010) Systematic review of the health benefits of physical activity and fitness in school-aged children and youth. Int J Behav Nutr Phys Act. 7, 40: 1-16.

Jiang L, Tian W, Wang Y, Rong J, Bao C, Liu Y and Wang C (2012) Body mass index and susceptibility to knee osteoarthritis: a systematic review and meta-analysis. Joint Bone Spine. 79: 291-297.

Kim Y, Umeda M, Lochbaum M and Stegemeier S (2016) Physical activity, screenbased sedentary behavior, and sleep duration in adolescents: Youth risk behavior survey, 2011-2013. Prev Chronic Dis. 13, 160245. DOI= http://dx.doi.org/10.58 88/pcd13.160245

Lauby-Secretan B, Scoccianti C, Loomis D, Grosse Y, Bianchini F and Straif K (2016) Body fatness and cancer - viewpoint of the IARC Working Group. N Engl J Med. 375: 794-8.

Lee I, Shiroma E, Lobelo F, Puska P, Blair S and Katzmarzyk P (2012) Effect of physical inactivity on major non-communicable diseases worldwide: an analysis of burden of disease and life expectancy. Lancet. 380, 9838: 219-29. DOI=10.10 16/S0140-6736(12)61031-9.

Liu Y, Wheaton A G, Chapman D P and Croft J B (2013) Sleep duration and chronic diseases among US adults age 45 years and older: evidence from the 2010 Behavioral Risk Factor Surveillance System. Sleep. 36: 1421-1427.

Mayo Clinic (2015) Healthy lifestyle: adult health. Retrieved from http://www.mayo clinic.org/healthy-lifestyle/adult-health/in-depth/napping/art-20048319.

Moore S C, Patel A V, Matthews C E, Berrington A, Park Y, Katki H A, Linet M S and Le I (2012) Leisure time physical activity of moderate to vigorous intensity and mortality: a large pooled cohort analysis. PLOS Med. 9, 11, e1001335. DOI= 10.1371/journal.pmed.1001335 
Naska A, Oikonomou E, Trichopoulou A, Psaltopoulo T and Trichopoulos D (2007) Siesta in healthy adults and coronary mortality in the general population. Arch Intern Med. 167, 3, 296-301. Retrieved from http://jamanetwork.com/journals/ja mainternalmedicine/fullarticle/411678.

National Academies of Sciences, Engineering, \& Medicine (2016) Assessing prevalence and trends in obesity: navigating the evidence. (Washington, D.C.). The National Academies Press. DOI= 10.17226123505.

National Center for Statistics (2016) Health, United States, 2015: With special features on racial and ethnic health disparities. (Hyattsville, MD). US Department of Health and Human Services. Retrieved from https://www.cdc.gov/nchs/data/hus/hus15. pdf\#053.

National Institute of Diabetes and Digestive and Kidney Diseases (2012) Health risks of being overweight. Retrieved from https://www.niddk.nih.gov/health-informati on/health-topics/weight-control/health_risks_being_overweight/Pages/health-ris ks-being-overweight.aspx\#top

National Institute of Neurological Disorders and Stroke (2014) Brain basics: Understanding sleep. Retrieved from http://www.ninds.nih.gov/disorders/brain basics/understanding_sleep.htm.

Ogden C L, Carroll M D, Fryar C D and Flegal K M (2015) Prevalence of obesity among adults and youth: United States, 2011-2014. National Center for Health Statistics Data Brief. 219: 1-8. (Hyattsville, MD).

Organisation for Economic Co-operation and Development. (2017) OECD: Greeks work more hours than all Europeans. Retrieved from http://greece.greekreporter. com/2017/01/06/oecd-greeks-work-more-hours-than-all-europeans/

Orlich M J, Singh P N, Sabaté J, Jaceldo-Siegl K, Fan J, Knutsen S and Fraser G E (2013) Vegetarian dietary patterns and mortality in Adventist Health Study 2. JAMA Intern Med. 173, 13: 1230-1238.

Panagiotakos D, Chrysohoou C, Pitsavos C and Stefanadis C (2006) Association between the prevalence of obesity and adherence to the Mediterranean diet: the ATTICA study. Nutrition. 22, 5, 449-456. Retrieved from http://www.nutritionjrnl.com/ar ticle/S0899-9007(05)00350-3/abstract

Panagiotakos D B, Chrysohoou C, Siasos G, Zisimos K, Skoumas J, Pitsavos C and Stefanadis C (2011) Sociodemographic and lifestyle statistics of oldest old people (> 80 years) living in Ikaria island: the Ikaria study. Cardiology Research and Practice. 2011, 1-7. DOI= http://dx.doi.org/10.4061/2011/679187

Papadopoulous P (2016) Discussion on June 21. Greek Ministry of Health. Athens, Greece.

Patel A V, Bernstein L, Deka A, Feigelson H S, Campbell P T, Bapstur S M, Colditz G A and Thun M J (2010) Leisure time spent sitting in relation to total mortality in a prospective cohort of US adults. Am J Epidemiol. 172, 4, 419-429. DOI= 10.109 3/aje/kwq155.

Pendick D (2014) Mediterranean-style diet linked to healthier arteries throughout the body. Retrieved from http://www.health.harvard.edu/blog/mediterranean-style-di et-linked-to-healthier-arteries-throughout-the-body-201401226996

Physical Activity Guidelines Advisory Committee (2008) 2008 Physical activity guidelines for Americans. Office of Disease Prevention \& Health Promotion, US Department of Health and Human Services. (October 2008). Retrieved from www. health.gov/paguidelines

Ploeg H, Chey T, Korda R, Banks E and Bauman A (2012) Sitting time and all-cause mortality risk in 222,497 Australian adults. Arch Intern Med. 172, 6: 494-500. DOI=10.1001/archinternmed.2011.2174. 
Population Pyramids (2017) Population pyramids of the world from 1950 to 2100: Greece 2017. Retrieved from https://populationpyramid.net/greece/.

Population Pyramids (2017b) Population pyramids of the world from 1950 to 2100: United States 2017. Retrieved from http://www.populationpyramid.net/united-sta tes-of-america/

Poulain M, Herm A and Pes G (2013) The Blue Zones: Areas of exceptional longevity around the world. Vienna Yearbook of Population Research. 87-108.

Rideout V J, Foehr U G and Roberts D F (2010) Generation M2: Media in the lives of $8-18$ year olds. Retrieved from http://www.kff.org/entmedia/mh012010pkg.cfm

Scarmeas N, Stern Y, Tang M, Mayeux R and Luchsinger J (2006) Mediterranean diet and risk for Alzheimer's disease. Ann Neurol. 59, 6, 912-921. Retrieved from https://www.ncbi.nlm.nih.gov/pmc/articles/PMC3024594/

Schiller J S, Ward B W, Freeman G and Clarke T C (2014) Early release of selected estimates based on data from the January - June 2014 National Health Interview Survey. National Center for Health Statistics. Retrieved from http://www.cdc. gov/nchs/nhis.htm

Singh GM, Danaei G, Farzadfar F, Stevens G A, Woodward M, Wormser D and Ezzati M (2013) The age-specific quantitative effects of metabolic risk factors on cardiovascular diseases and diabetes: a pooled analysis. PLOS ONE. 8, 7, e65174. DOI= https://doi.org/10.1371/journal.pone.0065174

Skinner A C, Perrin E M and Skelton J A (2016) Prevalence of obesity and severe obesity in US children, 1999-2014. Obesity. 24, 5, 1116-1123. DOI=10.1002/o by. 21497

Sofi F, Macchi C, Abbate R and Gensini G (2014) Mediterranean Diet and Health Status: an updated meta-analysis and a proposal for a literature-based adherence score. Public Health Nutrition.

The Mediterranean Diet Organization (2014) The Mediterranean diet pyramid has adapted to the new way of life. Retrieved from http://mediterradiet.org/nutrition/ mediterranean_diet_pyramid

The National Herald. 2016. Why Greek smoking ban doesn't work: Health minister breaks smoking laws. (May 31, 2016).

The National School of Public Health. n.d. Retrieved from http://www.esdy.edu.gr/ default.asp $x$ ?page $=$ home

The University of Athens. n.d. Retrieved from http://en.uoa.gr/

Tzotzas T, Kapantais E, Tziomalos K, Ioannidis I, Mortoglou A, Bakatselos S, and Kaklamonou D (2011) Prevalence of overweight and abdominal obesity in Greek children 6-12 years old: Results from the National Epidemiological Survey. Hippokratia. 15, 1: 48-53.

Ussery E N, Carlson S A, Whitfield G P, Watson K B, Berrigan D and Fulton J E (2017) Walking for transportation or leisure among U.S. women and men National Health Interview Survey, 2005-2015. MMWR. 66, 657-662. DOI= http://dx.doi.org/10.15585/mmwr.mm6625a1

U.S. Bureau of Labor Statistics (2016) American time use survey. Retrieved from https://www.bls.gov/tus/charts/sleep.htm.

U.S. Department of Agriculture (2006) Economic information: Bulletin number 9. Retrieved from http://ageconsearch.umn.edu/bitstream/59411/2/eib19.pdf

U.S. Department of Agriculture (2017) MyPlate. Retrieved from https://www.choose myplate.gov/MyPlate

U.S. Department of Health and Human Services (2008) Physical activity guidelines for Americans. Retrieved from https://health.gov/paguidelines/guidelines/. 
U.S. Department of Health and Human Services (2014) Preventing tobacco use among youth and young adults: A report of the surgeon general. Retrieved from https:// www.cdc.gov/tobacco/data_statistics/sgr/2012/index.htm.

U.S. Department of Health and Human Services (2015a) Step it up! The Surgeon General's call to action to promote walking and walkable communities. (Washington, DC). US Department of Health and Human Services, Office of the Surgeon General. Retrieved from https://www.surgeongeneral.gov/library/calls/walking-and-walka ble-communities/index.html

U.S. Department of Health and Human Services (2015b) The health consequences of smoking - 50 years of progress: a report of the surgeon general. Retrieved from https://www.cdc.gov/tobacco/data_statistics/sgr/50th-anniversary/index.htm.

U.S. Department of Health and Human Services and U.S. Department of Agriculture (2000) Nutrition and your health: Dietary guidelines for Americans. 5th Edition. Retrieved from https://health.gov/dietaryguidelines/dga2000/document/frontcov er.htm

U.S. Department of Health and Human Services and U.S. Department of Agriculture (2013) 2015 dietary guidelines advisory committee DGAC meeting 1: Materials and presentations. Retrieved from https://health.gov/dietaryguidelines/2015-bin der/meeting $1 /$ historycurrentuse.aspx

U.S. Department of Health and Human Services and U.S. Department of Agriculture (2015) Dietary Guidelines for Americans 2015-2020 eighth edition. Page 14. Retrieved from https://health.gov/dietaryguidelines/2015/resources/2015-2020_ Dietary_Guidelines.pdf

Watson K, Carlson S, Gunn J, Galuska D, O'Connor A, Greenlund K and Fulton J (2016) Physical inactivity among adults aged 50 years and older - United States, 2014. $M M W R$. 65, 954-958. DOI= http://dx.doi.org/10.15585/mmwr.mm6536a3

World Health Organization (2009) Tobacco the problem. Retrieved from http://www. who.int/nmh/publications/fact_sheet_tobacco_en.pdf

World Health Organization (2010) Global recommendations on physical activity for health. (Geneva Switzerland). Retrieved from http://www.who.int/dietphysicalac tivity/publications/9789241599979/en/

World Health Organization (2015) WHO report on the global tobacco epidemic: Greece. Retrieved from http://www.who.int/tobacco/surveillance/policy/country _profile/grc.pdf?ua=1.

World Health Organization (2015) Physical activity strategy for the WHO European Region 2016-2025. Retrieved from http://www.euro.who.int/_data/assets/pdf_ file/0010/282961/65wd09e_PhysicalActivityStrategy_150474.pdf.

World Health Organization (2017) Tobacco fact sheet. Retrieved from http://www. who.int/mediacentre/factsheets/fs339/en/ 
